\title{
Disease Modifying Anti-Rheumatic Drugs: Review on Pregnancy and Lactation
}

\author{
Tsz Yuen Wu*, King Yee Ying \\ Department of Medicine and Geriatrics, Princess Margaret Hospital, Hong Kong
}

\begin{abstract}
Rheumatic diseases occur commonly in patients of childbearing age. The compatibility of different Disease Modifying AntiRheumatic Drugs (DMARDs) during pregnancy and lactation can affect the management decision when treating these patients. With the development of promising biologics DMARDs (bDMARDs) and targeted synthetic DMARDs (tsDMARDs) in various rheumatic diseases, their safety in pregnancy and lactation is an issue for both patients and clinicians. Recently, three different guidelines on the compatibility of DMARDs during pregnancy and lactation has been published by ACR, EULAR and BSR respectively. This article summarizes their recommendations on the management of patients on DMARDs during pregnancy and lactation.
\end{abstract}

Keywords: Pregnancy; Lactation; csDMARDs; bDMARDs; tsDMARDs; Rheumatic Disease.

\section{INTRODUCTION}

Disease modifying anti-rheumatic drugs (DMARDs) are a group of medications which can modify the disease progression of the rheumatic diseases, which commonly occur in patients of childbearing age. It is important to clarify the compatibility of DMARDs in pregnancy, paternal exposure and lactation as this can affect the choice of drugs. Besides conventional synthetic disease modifying anti-rheumatic drugs (csDMARDs), there are various biologic DMARDs (bDMARDS) and targeted synthetic DMARDs (tsDMARDs) available. However, data regarding their safety in pregnancy and lactation is limited. In recent years, the American College of Rheumatology (ACR), European League against Rheumatism (EULAR) and the British Society for Rheumatology (BSR) have published their own guidelines on this aspect [1-4]. BSR has also made its recommendation on paternal compatibility on various DMARDs, which has far limited evidence available [3,4].
In a general population, it is estimated that 15 to $20 \%$ of pregnancies ended up in miscarriage and the background rate of congenital anomalies ranges between 1-5\% [5-7].

Since June 30, 2015, the US food and drug administration (FDA) has adopted a new system called the Pregnancy and Lactation Labelling Rule (PLLR) to replace the previous FDA letter category which has been used since 1979 [8]. There are several reasons why the old category has been replaced. In the FDA letter category, each drug is categorized into A, $\mathrm{B}, \mathrm{C}, \mathrm{D}, \mathrm{X}$ groups mainly based on the type of data available and the level of uncertainty, rather than the reproductive risk. However, the alphabetical order A, $\mathrm{B}, \mathrm{C}, \mathrm{D}, \mathrm{X}$ misleadingly implies increasing risk and this has led to unnecessary switching or discontinuation of the drugs in women contemplating pregnancy or pregnant women, or even unnecessary termination of pregnancy $[1,9]$. The new PLLR has eliminated the letter categories and the information is expressed in

\footnotetext{
(C) 2019 by the Hong Kong Society of Rheumatology and World Scientific Publishing Co. Pte. Ltd. O Open Access article under the CC BY-NC-ND license (http://creativecommons.org/licenses/by-nc-nd/4.0/).

Received 17 March 2019; Accepted 17 May 2019; Published 13 June 2019

*Corresponding author: Tsz-Yuen Wu, Department of Medicine and Geriatrics, Princess Margaret Hospital, 2-10 Princess Margaret Hospital Road, Lai Chi Kok, Kowloon, Hong Kong, E-mail: tomwu761@yahoo.com.hk
} 
narrative descriptions with a summary statement up front, followed by a clinical considerations section and supporting data. The hope is that this can provide more comprehensive information aiding physicians in assisting patients of childbearing age with family planning [8].

\section{MATERNAL COMPATIBILITY}

The recommendations from ACR, EULAR and BSR are summarized in Table 1.
All three parties agree that hydroxychloroquine, sulfasalazine, azathioprine, cyclosporin A, tacrolimus and TNF alpha inhibitor (TNFi) are compatible or relatively low risk during pregnancy [1-3]. High-risk medications which include methotrexate, mycophenolate mofetil, leflunomide or cyclophosphamide should be avoided during pregnancy and they should be stopped before conception with various durations of time [1-3]. Medications with insufficient evidence include rituximab, belimumab, tocilizumab, abatacept, anakinra,

Table 1. Comparison between ACR, EULAR and BSR suggestions about maternal compatibility.

\begin{tabular}{|c|c|c|c|}
\hline & ACR [1] & EULAR [2] & $\operatorname{BSR}[3,4]$ \\
\hline Hydroxychloroquine & Compatible & Compatible & Compatible \\
\hline Sulfasalazine & Compatible & Compatible & Compatible with $5 \mathrm{mg}$ folic acid/day \\
\hline Methotrexate & Not compatible & Not compatible & $\begin{array}{l}\text { Not compatible, stop at least } 3 \mathrm{mths} \\
\text { before conception }\end{array}$ \\
\hline Leflunomide & Not compatible & Insufficient data & Not compatible \\
\hline Azathioprine & Relatively low risk & Compatible & Compatible if $<2 \mathrm{mg} / \mathrm{kg}$ \\
\hline Cyclosporin A & Relatively low risk & Compatible & Compatible \\
\hline Tacrolimus & Relatively low risk & Compatible & Compatible \\
\hline Mycophenolate mofetil & Not compatible & Not compatible & $\begin{array}{l}\text { Not compatible, stop at least } 6 \text { wks before } \\
\text { conception }\end{array}$ \\
\hline Cyclophosphamide & Not compatible & $\begin{array}{l}\text { No. Or for severe, refractory } \\
\text { maternal disease in } 2^{\text {nd }}, 3^{\text {rd }} \\
\text { trimester if indicated. }\end{array}$ & Not compatible \\
\hline Intravenous immunoglobulin & Not mentioned & Compatible & Compatible \\
\hline TNF alpha inhibitor & $\begin{array}{l}\text { Comment as a group, } \\
\text { compatible, stop at } 30-32 \mathrm{wks}\end{array}$ & & \\
\hline Infliximab & & Compatible up to 20 wks & Compatible but stop at 16 wks \\
\hline Etanercept & & $\begin{array}{l}\text { Continued up to } 30-32 \text { wks, } \\
\text { if indicated, can continue } \\
\text { throughout pregnancy }\end{array}$ & Compatible but stop at $3^{\text {rd }}$ trimester \\
\hline Adalimumab & & Compatible up to 20 wks & Compatible but stop at $3^{\text {rd }}$ trimester \\
\hline Certolizumab & & $\begin{array}{l}\text { Compatible throughout } \\
\text { pregnancy }\end{array}$ & Compatible \\
\hline Golimumab & & $\begin{array}{l}\text { Limited data, alternative should } \\
\text { be considered }\end{array}$ & No data \\
\hline Rituximab & Insufficient data & Stop unless no other alternatives & No, stop at least $6 \mathrm{mths}$ before conception \\
\hline Belimumab & Insufficient data & Stop unless no other alternatives & No \\
\hline Tocilizumab & Insufficient data & Stop unless no other alternatives & No, stop at least $3 \mathrm{mths}$ before conception \\
\hline Abatacept & Insufficient data & Stop unless no other alternatives & No \\
\hline Anakinra & Insufficient data & Stop unless no other alternatives & No \\
\hline Ustekinumab & Insufficient data & Stop unless no other alternatives & Not mentioned \\
\hline Tofacitinib & Insufficient data & $\begin{array}{l}\text { Insufficient data, stop } 2 \mathrm{mths} \\
\text { before conception }\end{array}$ & Not mentioned \\
\hline
\end{tabular}


ustekinumab and tofacitinib. They should be avoided during pregnancy if possible [1-3].

Methotrexate (MTX) is contraindicated in pregnancy due to high risk of miscarriage $(25 \%)$ and congenital malformation (9-17\%), which includes cleft palate, hydrocephalus, anencephaly, meningoencephalocele, congenital stenosis of tubular long bones and abnormal facial features (low-set ears, micrognathia) etc. [10,11]. It is recommended to be stopped for 3 months before conception [3]. For women who have received lowdose MTX within 3 months prior to conception, folic acid $5 \mathrm{mg}$ per day should be prescribed prior to and throughout pregnancy. MTX is a folic acid antagonist and may theoretically induce maternal folic acid deficiency which may be harmful to the fetus $[3,12]$. For those with accidental pregnancy, MTX should be stopped immediately and folic acid $5 \mathrm{mg}$ per day should be prescribed [3]. Obstetrician should be informed to evaluate the fetal risk.

Leflunomide (LEF) is a high-risk medication according to ACR while both EULAR and BSR do not recommend leflunomide in pregnant women due to insufficient evidence. It has demonstrated embryotoxicity and marked teratogenicity, including neural tube defects, cleft palate and limb malformations in animal studies [10]. For women wishing to get pregnant, they should undergo either washout with cholestyramine ( $8 \mathrm{~g}$ TDS for 11 days) or drug discontinuation for 2 years prior to conception and a drug level check before pregnancy [1]. For those women taking leflunomide with accidental conception, leflunomide should be stopped immediately and cholestyramine washout should be administered until undetectable plasma levels are achieved [3]. According to leflunomide registry, women exposed to leflunomide in early pregnancy who undergone cholestyramine washout show no increase in adverse pregnancy outcomes [13].

Mycophenolate mofetil (MMF) is associated with miscarriage and congenital malformation including cleft lip and palate, anomalies of the distal limbs, heart, esophagus and kidneys [2,14]. A possible characteristic phenotype including cleft lip and palate, microtia, and external auditory canals has been reported in six cases [15]. It is contraindicated during pregnancy and should be withdrawn at least 6 weeks before pregnancy $[2,3,16]$. MMF has been demonstrated to have drugdrug interaction with combined oral contraceptives and significantly lower the level of the levonorgestrel level by $15 \%$ [16]. It is important to inform women on MMF that the drug may decrease the effectiveness of oral contraceptives and they should seek alternative contraception [16].

Cyclophosphamide can cause congenital malformations with a specific pattern termed "cyclophosphamide embryopathy", which includes growth restriction, ear and facial abnormalities, absence of digits and hypoplastic limbs [17]. According to the drug information, female should avoid pregnancy for up to 1 year [18]. The risk of teratogenicity is highest during the $1^{\text {st }}$ trimester. Its use in the $2^{\text {nd }}$ and $3^{\text {rd }}$ trimesters may be associated with low birth weight and neonatal pancytopenia. Its use might be justified in life-threatening conditions after the $1^{\text {st }}$ trimester $[2,19,20]$. Because cyclophosphamide can induce infertility, it is necessary to inform patients and discuss the various methods to preserve fertility. For females, feasible methods include cryopreservation of embryos or mature oocytes. Gonadotropin-releasing hormone (GnRH) agonists theoretically suppress ovarian function and may protect the ovary from toxic insult. However, the ovarian follicles remain exposed to the DNA damaging effect and its benefit is unproven. It should be used 10 to 14 days prior to initiation of cyclophosphamide [21].

Sulfasalazine has not been shown to have any increase risk for miscarriage or congenital malformation. Although neural tube defects have been reported, the causal relationship has not been established. Sulfasalazine inhibits absorption and metabolism of folic acid and periconceptional folic acid supplementation can decrease the risk of neural tube defects. It is recommended that folate supplement $5 \mathrm{mg}$ per day should be prescribed with sulfasalazine throughout the pregnancy $[2,3]$.

For biologics, which are either monoclonal antibodies or fusion proteins, the placental transfer to the fetus is related to the Fc portion. Neonatal $F_{c}$ receptors $(F c R n)$ bind the $F_{c}$ portion of IgG and transport the antibodies across the placenta. The FcRn is not expressed by the placenta in the $1^{\text {st }}$ trimester but its expression increases with gestational age and IgG is efficiently transferred across placenta during the $3^{\text {rd }}$ trimester, hence causing elevated maternal IgG levels in the newborn $[22,23]$. This affects the compatibility of biologics during pregnancy. 
For TNFi, they do not associate with miscarriage and major birth defects [2,3]. However, the extensive placental transfer to fetus during the $3^{\text {rd }}$ trimester might cause immunosuppression of the newborn and increase the risk of postnatal infection [1,2]. It has been reported that a newborn exposed to infliximab throughout the pregnancy died of disseminated Bacillus CalmetteGuerin following BCG vaccination at 3 months old [24]. In order to minimize in utero exposure, different guidelines have different suggestions at the time to stop the biologics (Table 1). Infliximab has prolonged bioavailability and high rate of placental transfer and hence it should be stopped from 16 weeks of gestation for it to be undetectable in cord blood at delivery [3]. It is recommended to postpone the administration of live vaccines (e.g. BCG, rotavirus) in infants who have been exposed to TNFi in utero throughout the pregnancy till 6 months after birth [1-3] as TNFi (infliximab, adalimumab) can be detected in newborn blood up to 6 months after delivery [25].

Certolizumab is a synthesized pegylated Fab fragment without Fc portion so it would not be actively transferred across the placenta $[1,10]$. It is compatible with all three trimesters of pregnancy [2]. However, there is still a low placental transfer of the drugs via passive diffusion across the placenta and the safety of administering live vaccine in exposed infants is unknown $[1,26]$. According to latest version of drug labeling, it is recommended to wait a minimum of 5 months following the mother's last dose during pregnancy before administration of live vaccine.

For etanercept, its Fc portion is modified and its binding to cytotrophoblasts is not effective. Transplacental passage of etanercept to the neonate is less efficient and the cord etanercept levels is only $3.6-7.4 \%$ of maternal drug levels [27,28]. EULAR suggests that it can be continued up to 30 to 32 weeks of gestation and if indicated, it may be considered for use throughout pregnancy due to low rate of transplacental passage [2].

For golimumab, there are no adequate and wellcontrolled studies in pregnant women and hence data to support its use during pregnancy are lacking and alternatives should be used [2]. It should be used during pregnancy only if clearly needed.

For rituximab, belimumab, tocilizumab, abatacept, ustekinumab and anakinra, while unintentional exposure early in the $1^{\text {st }}$ trimester is unlikely to be harmful, there was insufficient data to recommend these medications during pregnancy [1-3]. Rituximab, belimumab, tocilizumab, abatacept and ustekinumab should be stopped at least 6 months, 4 months (after last dose), 3 months, 14 weeks (after last dose) and 15 weeks (after last dose) before conception respectively [3,29-31]. There is no published information to suggest how long anakinra should be stopped before conception.

For tofacitinib, animal studies show fetocidal and teratogenic effect at exposures higher than the maximum recommended human dose (MRHD). There are also reductions in live litter size, postnatal survival, and pup body weights at exposures higher than the MRHD [32]. EULAR has reviewed one case series (abstract) which includes 27 pregnancies. There is a higher miscarriage rate but there is concomitant MTX exposure. There is no increased rate of congenital malformation. Because of insufficient data, it should be stopped 2 months before conception [2].

\section{PATERNAL COMPATIBILITY}

For paternal compatibility, only BSR has made its suggestion and it is summarized in Table 2. However, it should be emphasized that most of the suggestions are based on limited evidence and the information should be interpreted with caution.

BSR concludes that hydroxychloroquine, sulfasalazine, azathioprine, cyclosporin A, tacrolimus, methotrexate, leflunomide, mycophenolate mofetil, intravenous immunoglobulin, infliximab, etanercept, adalimumab and rituximab are compatible with paternal exposure [3]. Cyclophosphamide is regarded as high-risk medication and it should be avoided [3]. Medications with insufficient evidence include certolizumab, golimumab, belimumab, tocilizumab, abatacept, anakinra, ustekinumab and tofacitinib. They should be avoided if possible [3].

Sulfasalazine is compatible with paternal exposure based on low quality studies. However, it is associated with oligospermia, reduced sperm mobility and increase proportion of abnormal sperm. The effect is reversible and sperm quality improves if the drug is stopped for more than 12 months [3].

For IVIG, there is no study to assess the paternal exposure. However, based on maternal compatibility, BSR comments that it is unlikely to be harmful and compatible with paternal exposure [3]. 
Table 2. BSR suggestion of paternal compatibility.

\begin{tabular}{|c|c|c|c|}
\hline & BSR suggestion [3] & Studies & No. of subjects \\
\hline Hydroxychloroquine & Yes, limited data & 1 cohort, 1 case series & 13 \\
\hline Sulfasalazine & Yes & 3 cohort, 1 case control & 237 \\
\hline Methotrexate & Yes & 4 cohorts, 3 case series, 1 case report & 263 \\
\hline Leflunomide & Yes, limited data & 1 cohort, 1 case report & 2 \\
\hline Azathioprine & Yes & 6 cohort, 1 case control, 2 case series & 602 \\
\hline Cyclosporin A & Yes, limited data & 2 cohort, 2 case series & 254 \\
\hline Tacrolimus & Yes, limited data & 3 cohort & 120 \\
\hline Mycophenolate mofetil & Yes, limited data & 3 cohort & 72 \\
\hline Cyclophosphamide & No & No study identified & \\
\hline IVIG & Yes & No study identified & \\
\hline $\begin{array}{l}\text { Infliximab, } \\
\text { Etanercept, } \\
\text { Adalimumab }\end{array}$ & Yes, limited data & 5 cohort, 2 case series, 1 case-control study & 131 \\
\hline Certolizumab & No data & & \\
\hline Golimumab & No data & & \\
\hline Rituximab & Yes, limited data & 1 cohort & 11 \\
\hline Belimumab & No data, unlikely to be harmful & & \\
\hline Tocilizumab & No data, unlikely to be harmful & & \\
\hline Abatacept & No data, unlikely to be harmful & & \\
\hline Anakinra & No data, unlikely to be harmful & & \\
\hline
\end{tabular}

For the risk of paternal exposure with methotrexate, drug labeling from FDA suggests men should wait at least 3 months before conception [34]. BSR has reviewed 4 cohorts, 3 case series and 1 case report including 263 pregnancies; it has concluded that low-dose MTX may be compatible with paternal exposure [3].

For leflunomide, although BSR comments that it may be compatible with paternal exposure, the suggestion is based on 1 cohort and 1 case report which only included 2 pregnancies with paternal exposure to leflunomide within 3 months of conception and subsequent paternal exposure in at least 1 case with no reported washout. There is no adverse fetal outcome identified [3]. As the drug is detected in human semen and animal studies have not been conducted, drug labeling of teriflunomide (active metabolite of leflunomide) suggests that men wishing to father a child should undergo washout or wait until verification that the plasma drug metabolite concentration is less than $0.02 \mathrm{mg} / \mathrm{L}$ [33].
For cyclophosphamide, there is no established human data. However, study of male rats shows that there are higher rates of fetal loss and malformations. According to drug labeling from FDA, male patients should avoid conception for up to 4 months [35]. It can also decrease fertility in men. Cryopreservation of semen can be considered to preserve male fertility. Testosterone $100 \mathrm{mg}$ IM every 15 days may be useful as shown in a small study [36].

It should be noted that tofacitinib and ustekinumab are not reviewed by BSR. There is a cohort study of prenatal (maternal/paternal) exposure to tofacitinib in patients with ulcerative colitis. It identifies 14 cases with paternal exposure and no congenital malformation is found [37]. There is no study for ustekinumab on paternal exposure.

\section{BREASTFEEDING}

The compatibility of DMARDs with breastfeeding is summarized in Table 3. 
Table 3. Summary of ACR, EULAR, BSR compatibility of DMARDs with breastfeeding.

\begin{tabular}{llll}
\hline & ACR [1] & EULAR [2] & BSR [3] \\
\hline Hydroxychloroquine & Compatible & Compatible & Compatible \\
Sulfasalazine & Compatible & Compatible & Compatible \\
Methotrexate & Incompatible & Avoid, limited data & Incompatible \\
Leflunomide & Incompatible & Avoid, no data & No data \\
Azathioprine & Insufficient data & Compatible & Compatible \\
Cyclosporin A & Insufficient data & Compatible & Compatible, limited data \\
Tacrolimus & Insufficient data & Compatible & Compatible, limited data \\
Mycophenolate mofetil & Incompatible & Avoid, no data & Incompatible \\
Cyclophosphamide & Incompatible & Avoid, limited data & Incompatible \\
IVIG & Compatible & Compatible & Compatible \\
TNFi & Not mentioned & Compatible & Compatible except golimumab \\
Rituximab & Insufficient data & Avoid, no data & No data \\
Belimumab & Insufficient data & Avoid, no data & No data \\
Tocilizumab & Insufficient data & Avoid, no data & No data \\
Abatacept & Insufficient data & Avoid, no data & No data \\
Ustekimumab & Not mentioned & Avoid, no data & Not mentioned \\
Anakinra & Not mentioned & Avoid no data & No data \\
Tofacitinib & Insufficient data & Avoid, no data & Not mentioned \\
\hline
\end{tabular}

Hydroxychloroquine and sulfasalazine are compatible with breastfeeding. However, for sulfasalazine, its active metabolite can displace bilirubin and it should be avoided in premature infants, infants with hyperbilirubinemia or infants deficient in G6PD [46]. For azathioprine, cyclosporin $\mathrm{A}$ and tacrolimus, ACR suggests that further research is necessary and breastfeeding should be avoided [1]. However, EULAR and BSR suggest that women on these medications can continue breastfeeding based on limited evidence [2,3]. These 3 medications can be secreted at very low levels in breast milk [38-41]. However, based on small studies, there is no adverse effects on infants observed when their nursing mothers used these three drugs $[40,42]$. It is recommended to avoid breastfeeding for 4 hours after a dose of azathioprine and this can markedly decrease the dose received by the infant through breastfeeding [43]. For cyclosporin A and tacrolimus, it is recommended that the breastfed infants should be monitored, possibly including measurement of serum levels to rule out toxicity if there is concern $[44,45]$.
For methotrexate, leflunomide, mycophenolate mofetil and cyclophosphamide, all three parties agree that these medications should be avoided because of theoretical risk and insufficient data to support their use [1-3].

For TNFi, the level of drug at breast milk is low and hence most of them are compatible with breastfeeding. For golimumab, although there is no clinical data to support its use during lactation, EULAR comments that it is compatible with breastfeeding as it is a large protein molecule and absorption is unlikely due to low bioavailability $[2,3]$.

Rituximab, belimumab, tocilizumab, abatacept, ustekimumab, anakinra and tofacitinib have no data on compatibility with breastfeeding and they should be avoided during lactation.

\section{CONCLUSION}

Current suggestions from ACR, EULAR, BSR and drug labels are summarized in Table 4. These guidelines offer guidance for managing patients with rheumatic diseases in pregnancy. Patients planning to start a family should 
Table 4. Summary of the DMARDS in pregnancy, paternal exposure and lactation.

\begin{tabular}{|c|c|c|c|}
\hline Drug & Maternal & Paternal & Lactation \\
\hline Hydroxychloroquine & Compatible & Compatible & Compatible \\
\hline Sulfasalazine & $\begin{array}{l}\text { Compatible } \\
\text { Folic acid } 5 \mathrm{mg} / \text { day }\end{array}$ & Compatible & $\begin{array}{l}\text { Compatible } \\
\text { Avoid if premature infants, infants } \\
\text { with hyperbilirubinemia, or G6PD } \\
\text { deficiency }\end{array}$ \\
\hline Methotrexate & $\begin{array}{l}\text { Contraindicated } \\
\text { Stop } 3 \mathrm{mths} \text { folic acid } \\
5 \mathrm{mg} / \text { day }\end{array}$ & $\begin{array}{l}\text { May be compatible } \\
\text { Drug label: Stop } 3 \text { mths before } \\
\text { conception }\end{array}$ & Avoid \\
\hline Leflunomide & $\begin{array}{l}\text { Contraindicated } \\
\text { Stop } 2 \text { yrs/washout }\end{array}$ & $\begin{array}{l}\text { May be compatible } \\
\text { Drug label: Stop/washout }\end{array}$ & Avoid \\
\hline Azathioprine & $2 \mathrm{mg} / \mathrm{kg} /$ day & Compatible & $\begin{array}{l}\text { EULAR/BSR: Compatible } \\
\text { ACR: Insufficient } \\
\text { LactMed: withhold breastfeeding } \\
\text { for } 4 \text { hrs since last dose }\end{array}$ \\
\hline Cyclosporin A & Compatible & Compatible & $\begin{array}{l}\text { EULAR/BSR: Compatible } \\
\text { ACR: Insufficient } \\
\text { LactMed: check infant serum drug level }\end{array}$ \\
\hline Tacrolimus & Compatible & Compatible & $\begin{array}{l}\text { EULAR/BSR: Compatible } \\
\text { ACR: Insufficient } \\
\text { LactMed: check infant serum drug level }\end{array}$ \\
\hline Mycophenolate mofetil & $\begin{array}{l}\text { Contraindicated } \\
\text { Stop } 6 \text { wks before conception }\end{array}$ & May be compatible & Avoid \\
\hline Cyclophosphamide & $\begin{array}{l}\text { Contraindicated } \\
\text { Stop } 1 \text { yr before conception }\end{array}$ & Stop 4 mths & Avoid \\
\hline IVIG & Compatible & Compatible & Compatible \\
\hline Infliximab & $\begin{array}{l}\text { Compatible/ } \\
\text { Stop after } 16 \text { wks }\end{array}$ & Compatible & Compatible \\
\hline Etanercept & $\begin{array}{l}\text { Compatible/ } \\
\text { Stop after } 30 \text { wks }\end{array}$ & Compatible & Compatible \\
\hline Adalimumab & $\begin{array}{l}\text { Compatible/ } \\
\text { Stop after } 20 \text { wks }\end{array}$ & Compatible & Compatible \\
\hline Certolizumab & Compatible & Insufficient data & Compatible \\
\hline Golimumab & $\begin{array}{l}\text { Compatible } \\
\text { No data when to stop }\end{array}$ & Insufficient data & No data \\
\hline Rituximab & Stop $6 \mathrm{mths}$ before & Compatible & No data \\
\hline Belimumab & Stop $4 \mathrm{mths}$ before & No data & No data \\
\hline Tocilizumab & Stop $3 \mathrm{mths}$ before & No data & No data \\
\hline Abatacept & Stop 14 wks before & No data & No data \\
\hline Anakinra & No data & No data & No data \\
\hline Ustekinumab & Stop 15 wks before & No data & No data \\
\hline Tofacitinib & Stop $2 \mathrm{mths}$ before & No data & Insufficient \\
\hline
\end{tabular}

be well informed on the safety of different DMARDs in pregnancy, possible need for drug switching or discontinuation, duration of discontinuation before conception, effect on pregnancy and fetal outcome. A management plan should be made, taking into account disease controland safety of drug usage before conception, throughout pregnancy and/or breastfeeding. Hopefully in the near future, there would be more supportive data 
on the safety of these medications, especially new agents in pregnancy and/or lactation.

\section{REFERENCES}

[1] Kavanaugh A, Cush JJ, Ahmed MS, et al. Proceedings from the American College of Rheumatology Reproductive Health Summit: The Management of Fertility, Pregnancy, and Lactation in Women with Autoimmune and Systemic Inflammatory Diseases. Arthritis Care Res. 2015 Mar;67(3):313-25.

[2] Götestam Skorpen C, Hoeltzenbein M, Tincani A, et al. The EULAR points to consider for use of antirheumatic drugs before pregnancy, and during pregnancy and lactation. Ann Rheum Dis. 2016 May;75(5):795-801.

[3] Flint J, Panchal S, Hurrell A, et al. BSR and BHPR guideline on prescribing drugs in pregnancy and breastfeeding-Part I: standard and biologic disease modifying anti-rheumatic drugs and corticosteroids. Rheumatology. 2016 Sep;55(9):1693-7.

[4] Flint J, Panchal S, Hurrell A, et al. BSR and BHPR guideline on prescribing drugs in pregnancy and breastfeeding-Part II: analgesics and other drugs used in rheumatology practice. Rheumatology. 2016 Sep;55(9):1698-1702.

[5] Ventura SJ, Curtin SC, Abma JC, Henshaw SK. Estimated pregnancy rates and rates of pregnancy outcomes for the United States, 1990-2008. Natl Vital Stat Rep. 2012 Jun 20;60(7): 1-21.

[6] Bird TM, Hobbs CA, Cleves MA, Tilford JM, Robbins JM. National rates of birth defects among hospitalized newborns. Birth Defects Res A Clin Mol Teratol. 2006 Nov;76(11):762-9.

[7] Beaupre J, Erickson K, Danielson R. North Dakota birth defects monitoring system summary report 2001-2005. North Dakota: North Dakota Department of Health; 2009 Dec.111p.

[8] U.S. Food \& Drug administration (FDA). Pregnancy and Lactation Labeling (Drugs) Final Rule; 2014 Mar 12 [updated 2018 Jun 28; cited 2018 Mar 8]. https://www.fda.gov/Drugs/ DevelopmentApprovalProcess/DevelopmentResources/ Labeling/ucm093307.htm.

[9] Johnson T. Pregnancy and Lactation Labeling Rule (PLLR). United States: Division of Pediatric and Maternal Health FDA/ CDER/OND/ODEIV; 2016 Apr 14 [cited 2018 Mar 8]. https:// www.fda.gov/downloads/AboutFDA/WorkingatFDA/ Fellowshipinternshipgraduatefacultyprograms/pharmacy studentexperientialprogramcder/ucm495961.pdf.

[10] Bermas BL. Safety of anti-inflammtory and immunosuppressive drugs in rheumatic diseases during pregnancy and lactation. In: Furst DE, Lockwood CJ, Romain PL (eds.) Waltham(MA): UpToDate Inc; 2018 [updated 2018 Jul 23, cited 2018 Sep 1]. https://www.uptodate.com/contents/safety-of-anti inflammatory-and-immunosuppressive-drugs-in-rheumaticdiseases-during-pregnancy-and-lactation?search=DMARDS\% 20pregnancy\&source $=$ search_result\&selectedTitle $=1^{\sim} 144$ \&usage_type=default\&display_rank $=1 \# H 17$.

[11] Weber-Schoendorfer C, Chambers C, Wacker E, et al. Pregnancy outcome after methotrexate treatment for rheumatic disease prior to or during early pregnancy: a prospective multicenter cohort study. Arthritis Rheumatol. 2014;66(5):1101-10.
[12] Use of methotrexate in pregnancy. UK: UKTIS; 2016 [updated 2016 Apr, cited 2018 Apr 8]. http://www.medicinesinpregnancy. org/bumps/monographs/USE-OF-METHOTREXATE-INPREGNANCY/?print $=y$.

[13] Chambers CD, Johnson DL, Robinson LK, et al. Birth outcomes in women who have taken leflunomide during pregnancy. Arthritis Rheum. 2010 May;62(5):1494-503.

[14] Hoeltzenbein M, Elefant E, Vial T, et al. Teratogenicity of mycophenolate confirmed in a prospective study of the European Network of Teratology Information Services. Am J Med Genet A. $2012 \mathrm{Mar} ; 158 \mathrm{~A}(3): 588-96$.

[15] Perez-Aytes A, Ledo A, Boso V, Sáenz P, Roma E, Poveda JL. In utero exposure to mycophenolate mofetil: a characteristic phenotype? Am J Med Genet Part A. 2007;146A(1):1-7.

[16] Mycophenolate mofetil [Package insert on the internet]. FDA, USA: Genetech USA Inc; 2013 [updated 2013 Sep, cited 2018 Aug 8]. https://www.accessdata.fda.gov/drugsatfda_docs/ label/2015/050722s033,050723s032,050758s030,050759s038lbl. pdf

[17] Enns GM, Roeder E, Chan RT, Ali-Khan Catts Z, Cox VA, Golabi M. Apparent cyclophosphamide (Cytoxan) embryopathy: a distinct phenotype? Am J Med Genet. 1999 Sep 17;86(3): 237-41.

[18] Cyclophosphamide [Package insert on the internet]. DailyMed, USA: Amnel biosciences LLC [updated 2018 May 30; cited 2018 Aug 8]. https://dailymed.nlm.nih.gov/dailymed/drugInfo. cfm?setid=520bfe39-dfd5-4a20-9a37-80078afded0d\#LINK_ d9ffbe60-9b35-4f9f-bbd5-61c2cc572772.

[19] Berry DL, Theriault RL, Holmes FA, et al. Management of breast cancer during pregnancy using a standardized protocol. J Clin Oncol. 1999 Mar;17(3):855-61.

[20] Ring AE, Smith IE, Jones A, Shannon C, Galani E, Ellis PA. Chemotherapy for breast cancer during pregnancy: an 18-year experience from five London teaching hospitals. J Clin Oncol. 2005 Jun 20;23(18):4192-7.

[21] McCune JW, Clowse MB. General principles of the use of cyclophosphamide in rheumatic diseases. In: Furst DE, Curtis MR (eds.) Waltham (MA): UpToDate Inc: 2018 [updated 2018 Aug 6, cited 2018 Aug 8]. https://www.uptodate.com/contents/ general-principles-of-the-use-of-cyclophosphamide-inrheumatic-diseases.

[22] Palmeira P, Quinello C, Silveira-Lessa AL, Zago CA, CarneiroSampaio M. IgG placental transfer in healthy and pathological pregnancies. Clin Dev Immunol. 2012 [cited 2018 Aug 9] 985646, 13p. https://www.hindawi.com/journals/jir/2012/985646/

[23] Malek A, Sager R, Kuhn P, Nicolaides KH, Schneider H. Evolution of maternofetal transport of immunoglobulins during human pregnancy. Am J Reprod Immunol. 1996 Nov;36(5): 248-55.

[24] Cheent K, Nolan J, Shariq S, Kiho L, Pal A, Arnold J. Case report: fatal case of disseminated BCG infection in an infant born to a mother taking infliximab for Crohn's disease. J Crohns Colitis. 2010 Nov;4(5):603-5.

[25] Mahadevan U, Wolf DC, Dubinsky M, et al. Placental transfer of anti-tumor necrosis factor agents in pregnant patients with inflammatory bowel disease. Clin Gastroenterol Hepatol. 2013;11(3):286-92; quiz e24. 
[26] Cerotlizumab [Package insert on the internet]. FDA, USA: UCB Inc; 2017 [revised 2018 May, cited 2018 Aug 9]. https://www. accessdata.fda.gov/drugsatfda_docs/label/2017/125160s270lbl. pdf. Accessed Jan 2017.

[27] Murashima A, Watanabe N, Ozawa N, Saito H, Yamaguchi K. Etanercept during pregnancy and lactation in a patient with rheumatoid arthritis: drug levels in maternal serum, cord blood, breast milk and the infant's serum. Ann Rheum Dis. 2009 Nov;68(11):1793-4.

[28] Berthelsen BG, Fjeldsøe-Nielsen H, Nielsen CT, Hellmuth E. Etanercept concentrations in maternal serum, umbilical cord serum, breast milk and child serum during breastfeeding. Rheumatology. 2010 Nov;49(11):2225-7.

[29] Belimumab [Package insert on the internet]. FDA, USA: Human Genome Sciences Inc; 2017 [revised 2018 Jun, cited 2018 Aug 9] https://www.accessdata.fda.gov/drugsatfda_docs/label/ 2018/125370s062,761043s002lbl.pdf

[30] Drugs.com[Internet]. Multum C: Drugs.com. Abatacept pregnancy and breastfeeding warnings; [reviewed 2017 Sep 13, cited 2018 Aug 9]. https://www.drugs.com/pregnancy/abatacept. html.

[31] Drugs.com[Internet]. Multum C: Drugs.com. Ustekinumab pregnancy and breastfeeding warnings; [reviewed 2018 Sep 3, cited 2018 Sep 28]. https://www.drugs.com/pregnancy/ ustekinumab.html.

[32] Tofacitinib [Package insert on the internet]. FDA, USA: Pfizer Labs; 2012 [revised 2018 May, cited 2018 Sep 10]. https://www. accessdata.fda.gov/drugsatfda_docs/label/2018/203214s021, 208246s007lbl.pdf

[33] Teriflunomide [Package insert on the internet]. FDA, USA: Genzyme Cor; 2012 [revised 2016 Nov, cited 2018 Sep 10]. https://www.accessdata.fda.gov/drugsatfda_docs/label/2016/ 202992s002lbl.pdf

[34] Methotrexate [Package insert on the internet]. FDA, USA: Dava Pharms Inc; 2003 [revised 2018 Mar, cited 2018 Sep 10]. https:// www.accessdata.fda.gov/drugsatfda_docs/label/2018/ 008085s068lbl.pdf

[35] Cyclophosphamide [Package insert on the internet]. FDA, USA: Baxter International Inc; 1959 [revised 2014 Jan, cited 2018 Sep 10]. https://www.accessdata.fda.gov/drugsatfda_docs/ label/2014/040745Orig1s003lbl.pdf
[36] Masala A, Faedda R, Alagna S, et al. Use of testosterone to prevent cyclophosphamide-induced azoospermia. Ann Intern Med. 1997 Feb 15;126(4):292-5.

[37] Mahadevan U, Dubinsky MC, Su C, et al. Outcomes of pregnancies with maternal/paternal exposure in the tofacitinib safety databases for ulcerative colitis. Inflamm Bowel Dis. 2018 Jul 2 [cited 2018 Sep 10]. https://academic.oup.com/ibdjournal/ advance-article/doi/10.1093/ibd/izy160/5047917

[38] Christensen LA, Dahlerup JF, Nielsen MJ, Fallingborg JF, Schmiegelow K. Azathioprine treatment during lactation. Aliment Pharmacol Ther. 2008 Nov 15;28(10):1209-13.

[39] Sau A, Clarke S, Bass J, Kaiser A, Marinaki A, Nelson-Piercy C. Azathioprine and breastfeeding: is it safe? BJOG 2007 Apr;114(4):498-501.

[40] Osadchy A, Koren G. Cyclosporin and lactation: when the mother is willing to breastfeed. Ther Drug Monit. 2011 Apr;33(2):147-8.

[41] Bramham K, Chusney G, Lee J, Lightstone L, Nelson-Piercy C. Breastfeeding and tacrolimus: serial monitoring in breast-fed and bottle-fed infants. Clin J Am Soc Nephrol. 2013 Apr;8(4): 563-7.

[42] Constantinescu S, Pai A, Coscia LA, Davison JM, Moritz MJ, Armenti VT. Breastfeeding after transplantation. Best Pract Res Clin Obstet Gynaecol. 2014 Nov;28(8):1163-73.

[43] Drugs and Lactation Database (LactMed) [Internet]. Bethesda (MD). National Library of Medicine (US);2006. Azathioprine [revised 2018 July, cited 2018 Sep 12]. https://www.ncbi.nlm. nih.gov/books/NBK501050/.

[44] Drugs and Lactation Database (LactMed) [Internet]. Bethesda(MD). National Library of Medicine (US);2006. Cyclosporin A [revised 2018 July, cited 2018 Sep 12]. https:// www.ncbi.nlm.nih.gov/books/NBK501683/.

[45] Drugs and Lactation Database (LactMed) [Internet]. Bethesda(MD). National Library of Medicine (US);2006. Tacrolimus; [revised 2018 July, cited 2018 Sep 12]. Available from: https://www.ncbi.nlm.nih.gov/books/NBK501104/.

[46] Sammaritano LR, Bermas BL. Chapter 39: Pregnancy and rheumatic diseases. In: Firestein GS, Budd RC, Gariel SE, Mclnnes IB, O’Dell JR (eds.) Kelley and Firestein's Textbook of Rheumatology (Tenth Edition), Elsevier, 2017. 